CARTAS AL EDITOR Rev Chil Salud Pública 2013; Vol 17 (3): 319-320

\title{
CARTA AL DIRECTOR DE LA REVISTA CHILENA DE SALUD PÚBLICA
}

IV Coloquio Latinoamericano de Biopolítica.

LETTERS FROM THE BIOPOLITICAL MEETING IN COLOMBIA

\section{Señores Revista Chilena de Salud Pública:}

Considerando que la salud pública es una noción que se alimenta entre otras cosas de las discusiones y los enfoques académicos, y que como todo alimento, estos pueden tener algunos efectos más saludables que otros, me permito algunas opiniones sobre el IV Coloquio Latinoamericano de Biopolítica y II Coloquio internacional de Biopolítica y Educación, que tuvo lugar entre el 3 y el 6 de septiembre en Bogotá, Colombia.

Desde un comienzo destacó la gran cantidad -al menos trece-, de instituciones organizadoras y patrocinantes, lo que habla muy bien del esfuerzo conjunto y de la capacidad de acuerdo de los organizadores. No obstante, en mi opinión, esta misma diversidad por momentos dio la impresión de que el evento era demasiado pequeño para dar espacios de protagonismo a las distintas instituciones y a los académicos locales: se hizo poca la torta, sobre todo cuando hay además una buena cantidad de invitados y participantes del extranjero. A esto se sumó también una suerte de escisión de rangos que fue en contra de las instancias de diálogo e intercambio igualitario que son el alma de este tipo de actividades: salvo excepciones, no se observó mayor participación de los conferencistas de las plenarias en las mesas de discusión del grueso de los participantes.

Respecto de los conferencistas, Thomas Lemke y Edgardo Castro pusieron denuedo en elaborar una cartografía de los distintos sentidos y usos que el vocablo de biopolítica ha adquirido a lo largo de su breve pero potente recorrido. Esto no deja de ser sintomático de las confusiones y a veces malos entendidos que parecen habitar bajo esta categoría. Y así, cuando se habla de biopolítica, si bien da la impresión que hablamos de lo mismo, al parecer queremos decir cosas distintas. Tienen lugar entonces numerosas discusiones sobre biopolíticas negativas y positivas, tanatopolíticas, cuestiones médicas y económicas, críticas al capitalismo, problemáticas identitarias, y por cierto, preguntas por el sentido que este sintagma ocupa en la obra de su principal profeta: Michel Foucault. En efecto, en su conferencia Santiago Castro-Gomez es llevado a sugerir una distinción entre los “foucaulteanos" y los "foucaultistas", para de este modo regular o al menos ordenar tanto las investigaciones de inspiración genealógica sobre problemas o coyunturas emergentes, como las interpretaciones y exégesis que buscan esclarecer conceptos y modulaciones al interior del trabajo de Foucault. ¿Será este el inicio de una fragmentación o de un proceso de reforma, o al contrario, significará la consolidación y el robustecimiento de una iglesia que ya cuenta con sus textos sagrados, sacerdotes, predicadores y hasta monaguillos?

Mención aparte merece la noción de neoliberalismo como vocablo que captura y explica todos los males del mundo. También de modo confuso, algunos autores llegaron a vincular biopolítica y neoliberalismo de modo solidario. De este modo, la biopolítica sería la estrategia perversa y oculta de 
este gran monstruo de afilados dientes que es el neoliberalismo, y del cual es imposible escapar y evadirse. A mi gusto, una débil aproximación metodológica, puesto que transforma el gesto crítico en una mera tarea de develar información sobre las retorcidas intenciones y procedimientos de los neoliberales, entregándoles muchas veces capacidades racionales y conspirativas que si se examinan de modo menos grandilocuente -tal vez desde la óptica de una hormiga-, se muestran mucho menos poderosas, más frágiles, y por tanto, otorgan un panorama mucho más fiel y menos apocalíptico de lo que se juega en las luchas. Aquellas luchas que, según el mismo Foucault, nunca son definitivas. Pero al contrario, al parecer algunos han descubierto el neoliberalismo después de que se tradujo El nacimiento de la biopolítica en el 2007, y con ello han encontrado la lógica que gobierna los procesos sufridos, por ejemplo en Chile, desde hace ya 40 años. El análisis de Foucault parece dispensar a algunos de atender a la minuciosa mecánica neoliberal, y sustituir su comprensión por un listado de culpables: Friedman, Schultz, Becker y otros, son los nombres de aquellos que han construído maquiavélicamente el mundo y que se hacen hoy acreedores de todo el desprestigio causal. Sacrificándolos y denunciando su monstruosidad, podemos sentirnos tranquilos de nuestra incisiva crítica, además de acomodarnos tranquilamente en los mutuos masajeos de conciencia moral de investigadores o académicos outsiders. Quisiera creer que el uso del trabajo de Foucault de la mano de los aportes de Callon y Latour podría llevarnos más allá de la mera consigna y la simple aceptación derrotada, como me pareció advertir en la conferencia de Nikolas Rose, indiscutida estrella del evento. Rose parece encontrar en la noción de resiliencia un entramado anfibológico que si bien alude a la exigencia funcional -por parte de instituciones y otros dispositivos-, de encontrar y recuperar fuerzas frente a las diversas formas de opresión, también indica la capacidad espontánea que tienen las comunidades de contenerse y elaborar mecanismos de aguante y resistencia frente a la inestabilidad que las invade en la era de los riesgos. Rose terminó preguntando por el tipo de sujeto que anida en esta disposición resiliente positiva de las comunidades. Yo demandaría por el tipo de política que cabe en una sociedad que se organiza únicamente para responder a la amenaza. Si se concede tan fácilmente lugar al fantasma del riesgo impredecible y al peligro inminente, la política se vacía de todo proyecto y de todo coeficiente de futuro. Como si no se pudiese pensar en una escena política diferente y solo nos quedase constituir formas de protegernos, de darnos ánimo y hacernos cariño ante un mundo que golpea permanentemente con el temor.

Pese a las palabras de Rose, me parece que algo distinto se ve en las calles de Bogotá. Pude asistir a uno de los cacerolazos que ratificaron el apoyo de la ciudadanía a los movimientos disidentes campesinos que se oponen al impacto del TLC. Entre arepas, pinturas en el piso, música y canelazos, y pese a la militarización en una ciudad invadida de instancias de vigilancia y control, da la impresión de que lo que se busca no es solo amortiguar sino inventar. Hay que decirlo: las palabras inaugurales de Santiago Castro-Gomez, fueron en esa dirección apelando a que "de una u otra forma somos todos agrodescendientes", y que por tanto, la voz de esa protesta es también la voz de muchos de los colombianos que quieren otra cosa. Me parecieron oportunas también las palabras de Alexis de Greiff, director de la biblioteca Luis Ángel Arango. El director se pronunció sobre la biblioteca como un lugar de encuentro - un encuentro material y de palabra-, por sobre la volatilidad y la distancia del libro electrónico y el encuentro virtual. Es que parece que un coloquio debe apuntar no solo a aquello sobre lo que se lee y se escribe, un coloquio se trata también de cómo aquello sobre lo que se lee y se escribe puede también encontrarnos y hasta enfrentarnos.

Tuillang Yuing

Doctor en Filosofía Universidad Mayor 